\title{
Radioiodine Ablation of Remaining Thyroid Lobe in Patients with Differentiated Thyroid Cancer Treated by Lobectomy: A Systematic Review and Metaanalysis
}

\author{
Arnoldo Piccardo*1, Pierpaolo Trimboli*2,3, Gianluca Bottoni ${ }^{1}$, and Luca Giovanella ${ }^{2,4}$ \\ ${ }^{1}$ Department of Nuclear Medicine, Galliera Hospital, Genoa, Italy; ${ }^{2}$ Clinic for Nuclear Medicine and Thyroid Centre, Imaging \\ Institute of Southern Switzerland, Ente Ospedaliero Cantonale, Bellinzona, Switzerland; ${ }^{3}$ Faculty of Biomedical Sciences, Università \\ della Svizzera Italiana, Lugano, Switzerland; and ${ }^{4}$ Clinic for Nuclear Medicine, University Hospital and University of Zurich, Zurich, \\ Switzerland
}

We aimed to conduct a systematic review and metaanalysis of studies reporting the performance of radioactive iodine $\left({ }^{131} I\right)$ therapy in differentiated thyroid cancer (DTC) patients requiring a completion treatment after lobectomy. We also evaluated the response to ${ }^{131}$ I therapy according to 2015 American Thyroid Association guidelines and the adverse events. Methods: A specific search strategy was designed to find articles evaluating the use of ${ }^{131}$ I in patients with evidence of DTC after lobectomy. PubMed, Cochrane Central Register of Controlled Trials, Scopus, and Web of Science were searched. The search was updated until January 2020, without language restriction. Data were cross-checked and any discrepancy discussed. A proportion metaanalysis (with 95\% confidence interval) was performed using the random-effects model. Metaregressions on ${ }^{131}$ I success were attempted. Results: The pooled success ablation rate was $69 \%$, with better results in patients receiving a single administration of about $3.7 \mathrm{GBq}$; high heterogeneity was found ( $\left(1^{2}\right.$ test, $\left.85 \%\right)$, and publication bias was absent (Egger test, $P=0.57$ ). Incomplete structural responses were recorded in only 14 of $695(2 \%)$ patients enrolled in our analysis. Incomplete biochemical responses were observed in $8 \%-24 \%$ of patients, with higher rates $(24 \%)$ in patients receiving low radioiodine activities $(\sim 1.1 \mathrm{GBq})$ and lower rates $(8 \%-18 \%)$ in patients receiving higher activities of radioiodine $(\sim 3.7 \mathrm{GBq})$. Neck pain due to thyroiditis was reported in up to $18 \%$ of patients, but in most cases, symptoms resolved after oral paracetamol or a short course of prednisone. Conclusion: Lobar ablation with ${ }^{131}$ I is effective, especially when high ${ }^{131} \mathrm{I}$ activities are used. However, the rate of incomplete biochemical response to initial treatment appears to be slightly higher than in the classic scheme of initial treatment of DTC. Radioisotopic lobectomy should be considered for patients with low- to intermediate-risk DTC requiring completion treatment after lobectomy due to specific individual risk factors or patient preferences.

Key Words: ${ }^{131}$ I therapy; lobectomy; DTC; metaanalysis

J Nucl Med 2020; 61:1730-1735

DOI: 10.2967/jnumed.120.244384

Received Feb. 29, 2020; revision accepted Mar. 28, 2020.

For correspondence or reprints contact: Arnoldo Piccardo, Department of Nuclear Medicine, E.O. Ospedali Galliera, Mura delle Cappuccine 14, 16128 Genoa, Italy.

E-mail: arnoldo.piccardo@galliera.it

${ }^{*}$ Contributed equally to this work.

Published online Apr. 24, 2020.

COPYRIGHT (C 2020 by the Society of Nuclear Medicine and Molecular Imaging.
A

more conservative approach to the clinical management of thyroid nodules and differentiated thyroid cancer (DTC) has recently been proposed by the 2015 American Thyroid Association guidelines (1). Indeed, fine-needle aspiration biopsy has been selectively proposed for nodules at higher risk on the basis of ultrasound features or dimensions. In addition, lobectomy, rather than thyroidectomy, has been proposed as the initial surgical procedure in most patients affected by low-risk DTC (1). Although lobectomy mostly avoids surgery-related complications (i.e., hypoparathyroidism and laryngeal nerve dysfunction), completion thyroidectomy may be required to provide complete resection of multicentric disease or in the case of unexpected extrathyroidal extension or lymph node involvement. The clinical outcome is similar in patients treated with total thyroidectomy and lobectomy followed by completion thyroidectomy (2). However, the risk of transient (9\%) or persistent hypocalcemia $(1.5 \%)$ and transient vocal cord paresis $(5 \%)$ is not negligible, especially if the second thyroid surgery is performed within $90 \mathrm{~d}$ after lobectomy (3). In addition, this 2-stage thyroidectomy is not well accepted and is often refused by patients for whom total thyroidectomy should have been initially recommended. In addition, a second surgical operation may be clinically contraindicated in patients with comorbidities or with evidence of complications after lobectomy.

Radioactive remnant ablation ( ${ }^{131}$ I therapy) has traditionally been reserved for DTC patients who have undergone total thyroidectomy, and particularly in those at risk of disease persistence or relapse after surgery. However, in the case of an unexpected diagnosis of DTC after lobectomy, ablation of the remaining lobe by means of ${ }^{131} \mathrm{I}$ has been proposed as an alternative to a second completion surgery (1). This noninvasive approach could be an attractive alternative to a second surgery. However, the available literature is limited, and the effectiveness and safety of radioisotopic lobectomy are uncertain. In view of this problem, we planned an updated systematic review and metaanalysis of studies reporting the performance of radioactive iodine $\left({ }^{131} \mathrm{I}\right)$ therapy in DTC patients who require a completion treatment after lobectomy. We also evaluated the response to ${ }^{131} \mathrm{I}$ therapy according to 2015 guidelines (1) and reported adverse events.

\section{MATERIALS AND METHODS}

The systematic review was performed in accordance with the guidelines of PRISMA (Preferred Reporting Items for a Systematic Review and Metaanalysis) (Fig. 1) (4). 


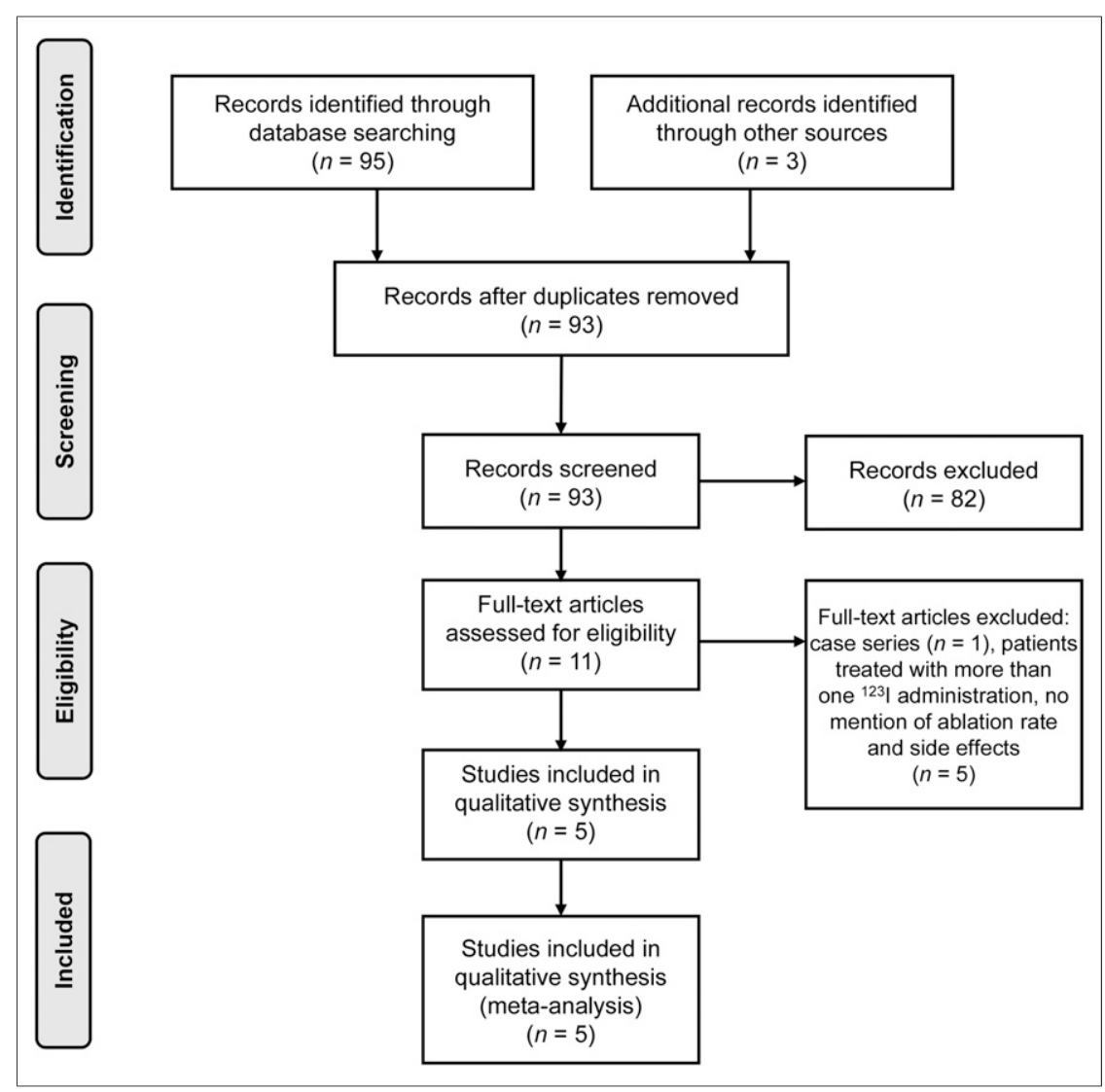

FIGURE 1. PRISMA flow diagram.

\section{Search Strategy}

A 4-step search strategy was adopted. First, sentinel studies were sought in PubMed. Second, keywords and MeSH (Medical Subject Headings) terms were identified in PubMed. Third, PubMed, Cochrane Central Register of Controlled Trials, Scopus, and Web of Science were searched. Fourth, we sought studies evaluating the use of ${ }^{131}$ I therapy for residual lobe ablation in patients with evidence of DTC after lobectomy in online databases (i.e., PubMed/ MEDLINE, Embase, Web of Science, and Scopus). The search was updated until January 31, 2020. No language restriction was used. To identify additional studies and expand our search, the references of the articles retrieved were also screened. Important overlapping data $(>25 \%)$ between several studies were excluded.

\section{Data Extraction}

The following information was extracted independently and in duplicate by 2 investigators in a piloted form: general information on the study (author, year of publication, country, study type, number of patients, and final diagnosis), ${ }^{131}$ I activity administered, and rate of successful ablation. For the extraction of data, main papers and supplementary data were searched; if data were missing, the authors were contacted via e-mail. Data were cross-checked, and any discrepancy was discussed.

\section{Study Quality Assessment}

The risk of bias of the studies included was assessed independently by 2 reviewers with regard to the following aspects: study design, patient selection, reporting, and reference standard. Risk of bias and concerns about applicability were rated as low, high, or unclear.

\section{Statistical Analysis}

A proportion metaanalysis was performed by means of a random-effects model. Pooled data were presented with $95 \%$ confidence interval. Heterogeneity among studies was assessed by means of the $\mathrm{I}^{2}$ test, with $50 \%$ or higher being regarded as high. Publication bias was assessed by means of the Egger test. Metaregressions on ${ }^{131} \mathrm{I}$ therapy success were attempted. All analyses were performed using Prometa 3.0 (Internovi) or StatsDirect software. A $P$ value of less than 0.05 was regarded as significant.

\section{RESULTS}

\section{Literature Search}

In total, 11 papers were found, and their titles and abstracts were analyzed; 4 were excluded because they were case series or did not

TABLE 1

Characteristics of Included Studies

\begin{tabular}{lllcl}
\hline \multicolumn{1}{c}{ Study } & Country & Design & Patients $(n)$ & Selection criteria \\
\hline Randolph (2002) & United States & Retrospective & 50 & $\begin{array}{c}\text { Thyroid cancer confirmed after lobectomy; } \\
\text { no distant metastases }\end{array}$ \\
\hline Hoyes (2004) & United Kingdom & Retrospective & 60 & $\begin{array}{c}\text { Thyroid cancer confirmed after lobectomy; } \\
\text { no distant metastases }\end{array}$ \\
\hline Bal (2006) & India & Prospective & 85 & $\begin{array}{c}\text { DTC confirmed after lobectomy, limited to } \\
\text { thyroid gland; negative neck ultrasound }\end{array}$ \\
\hline Santra (2011) & India & Retrospective & 364 & $\begin{array}{c}\text { Thyroid cancer confirmed after lobectomy, } \\
\text { limited to thyroid gland; negative neck ultrasound }\end{array}$ \\
\hline Giovanella (2013) & Switzerland & $\begin{array}{c}\text { Randomized and } \\
\text { prospective }\end{array}$ & 136 & $\begin{array}{c}\text { Unifocal DTC confirmed after lobectomy, limited to } \\
\text { thyroid gland; negative neck ultrasound }\end{array}$ \\
\hline
\end{tabular}


TABLE 2

Patient Characteristics, Therapeutic Protocol, and Ablation Criteria

\begin{tabular}{|c|c|c|c|c|c|c|c|c|c|}
\hline Study & Age (y) & Histology & $\mathrm{T}$ & $\mathrm{N}$ & Stage & $\begin{array}{c}{ }^{131} \text { I activity } \\
\text { (GBq) }\end{array}$ & $\begin{array}{c}\text { TSH } \\
\text { stimulation }\end{array}$ & $\begin{array}{l}\text { TSH at time } \\
\text { of }{ }^{131} \text { I therapy }\end{array}$ & $\begin{array}{l}\text { Ablation criteria } \\
\text { for each study }\end{array}$ \\
\hline $\begin{array}{l}\text { Randolph } \\
\text { (2002) }\end{array}$ & $\begin{array}{c}49.5 \\
\text { (mean) }\end{array}$ & $\begin{array}{l}\text { PTC }(60 \%), \text { FTC }(28 \%) \\
\text { HCC }(12 \%)\end{array}$ & pT1-pT4 & $\begin{array}{l}\text { N0 }(64 \%), \\
\text { N1 }(36 \%)\end{array}$ & $\mathrm{I}-\mathrm{IVa}$ & 1.1 & THW & $\underset{\text { (mean) }}{76 \mathrm{IU} / \mathrm{mL}}$ & NR \\
\hline $\begin{array}{l}\text { Hoyes } \\
\qquad(2004)\end{array}$ & $\begin{array}{c}51 \\
\text { (median) }\end{array}$ & $\begin{array}{l}\text { PTC (60\%), FTC (23\%), } \\
\text { HCC }(17 \%)\end{array}$ & NR & NR & NR & 3.5 & THW & NR & $\begin{array}{c}\text { Uptake }<1 \% \text { on } \\
\text { 131I DxWBS }\end{array}$ \\
\hline Bal (2006) & $\begin{array}{c}37.9 \\
\text { (mean) }\end{array}$ & PTC (76\%), FTC (24\%) & NR & No & NR & $\begin{array}{c}1.2 \\
\text { (mean) }\end{array}$ & THW & $\begin{array}{c}11.7 \mu \mathrm{IU} / \mathrm{mL} \\
\text { (mean) }\end{array}$ & $\begin{array}{l}\text { Uptake }<0.2 \% \text { on } \\
131 \text { I DxWBS and } \\
\mathrm{Tg}<10 \mathrm{ng} / \mathrm{mL}\end{array}$ \\
\hline $\begin{array}{l}\text { Santra } \\
\qquad(2011)\end{array}$ & $\begin{array}{c}38 \\
\text { (mean) }\end{array}$ & $\begin{array}{l}\text { PTC }(78 \%), \text { FTC }(20 \%) \\
\text { HCC }(6 \%)\end{array}$ & NR & NO & NR & $\begin{array}{l}1.47 \\
\text { (mean) }\end{array}$ & THW & NR & $\begin{array}{l}\text { Uptake }<0.2 \% \text { on } \\
131 \text { I DxWBS and } \\
\mathrm{Tg}<10 \mathrm{ng} / \mathrm{mL}\end{array}$ \\
\hline $\begin{array}{l}\text { Giovanella } \\
\text { (2013) }\end{array}$ & $\begin{array}{c}44 \\
\text { (mean) }\end{array}$ & $\begin{array}{l}\text { PTC }(57 \%) \text {, follicular } \\
\text { thyroid carcinoma } \\
(43 \%)\end{array}$ & $\begin{array}{l}\text { pT1 and } \\
\text { pT2 }\end{array}$ & NO & I-II & $\begin{array}{l}1.1(48 \%)- \\
3.7(52 \%)\end{array}$ & THW & $\begin{array}{l}>25 \mu \mathrm{lU} / \mathrm{mL} \\
\quad \text { in all patients }\end{array}$ & $\begin{array}{l}\text { Negative }{ }^{131} \mathrm{I} \\
\text { DxWBS and stimulated } \\
\mathrm{Tg}<2 \mathrm{ng} / \mathrm{mL}\end{array}$ \\
\hline
\end{tabular}

TSH = thyroid-stimulating hormone; PTC = papillary thyroid carcinoma; FTC = follicular thyroid carcinoma; HCC $=$ hepatocellular carcinoma; THW = thyroid hormone withdrawal; NR = not reported; DxWBS = diagnostic radioiodine whole-body scintigraphy; $\mathrm{Tg}=$ thyroglobulin.

American Thyroid Association successful ablation criteria are negative imaging and either suppressed thyroglobulin $<0.2 \mathrm{ng} / \mathrm{mL}$ or TSH-stimulated thyroglobulin $<1 \mathrm{ng} / \mathrm{mL}(1)$

analyze or mention at least one of the following issues: successful ablation rate, response to initial therapy (i.e., thyroidectomy and ${ }^{131} \mathrm{I}$ therapy) (1), and side effects. In addition, we excluded studies in which patients had been treated with more than a single ${ }^{131} \mathrm{I}$ administration and those in which the number of patients treated once was not inferable. Therefore, 5 articles were selected and 695 patients were finally included (5-9). The papers were published between 2002 and 2013 and had sample sizes ranging from 50 to 364 patients treated with ${ }^{131}$ I therapy for lobe ablation following a conservative surgical approach (i.e., lobectomy) and with a histologic diagnosis of DTC.

\section{Qualitative Analysis (Systematic Review)}

Three studies were retrospective and 2 prospective. Two studies were performed in India, 1 in the United States, 1 in the United Kingdom, and 1 in Switzerland. In 3 of the 5 studies, 22 patients affected by Hürthle cell carcinomas were included. The characteristics of the studies and patients and the therapeutic protocols are summarized in Tables 1 and 2. When the 1-y outcome after ${ }^{131} \mathrm{I}$ ablation was evaluated according to the 2015 American Thyroid Association guidelines, sufficient data were inferable from 4 of the 5 studies. The results are summarized in Table 3. Side effects were reported in 3 of the 5 studies. Specifically, Randolph et al. and Bal et al. reported neck pain in $18 \%$ and $15 \%$ of patients, respectively $(5,7)$. Giovanella et al. reported moderate neck pain in 34 of their 67 patients $(50.7 \%)$ treated with $1.1 \mathrm{GBq}$ and in 46 of the 69 treated with $3.7 \mathrm{GBq}(66 \%)(8)$.

\section{Quality Assessment of the Studies}

Risk of bias was assessed on the basis of 4 study characteristics; these results are reported in Table 4. In general, the risk of bias seemed to be high. Specifically, in 4 of 5 studies the patient selection and the quality of the standard of reference seemed to be suboptimal. In addition, the data in at least 3 of the 5 studies were not well described and reported.

\section{TABLE 3}

One-Year Response to Initial Therapy (Surgery Plus ${ }^{131}$ I) According to 2015 American Thyroid Association Guidelines (1)

\begin{tabular}{lccc}
\hline \multicolumn{1}{c}{ Study } & $\begin{array}{c}\text { Complete response (negative } \\
\text { imaging and suppressed } \\
\mathrm{Tg}<0.2 \mathrm{ng} / \mathrm{mL}(1))\end{array}$ & $\begin{array}{c}\text { Incomplete biochemical } \\
\text { response (negative imaging and } \\
\text { suppressed } \mathrm{Tg}>1 \mathrm{ng} / \mathrm{mL}(1))\end{array}$ & $\begin{array}{c}\text { Incomplete structural response } \\
\text { (structural or functional evidence } \\
\text { of disease with any Tg level (1)) }\end{array}$ \\
\hline Randolph (2002) & $28(76 \%)$ & $12(24 \%)$ & 0 \\
Hoyes (2004) & $49(82 \%)$ & $11(18 \%)$ & 0 \\
Bal (2006) & $\mathrm{NE}$ & $\mathrm{NE}$ & $\mathrm{NE}$ \\
Santra (2011) & $\mathrm{NE}$ & $\mathrm{NE}$ & $14(3.8 \%)$ \\
Giovanella (2013) & 51 treated with $1.1 \mathrm{GBq}(76 \%)$ & 16 treated with $1.1 \mathrm{GBq}(24 \%)$ & 0 \\
& 65 treated with $3.7 \mathrm{GBq}(92 \%)$ & 4 treated with $3.7 \mathrm{GBq}(8 \%)$ &
\end{tabular}

$\mathrm{NE}=$ not evaluable; $\mathrm{Tg}=$ thyroglobulin 
TABLE 4

Quality Assessment of Studies and Risk of Bias for Each Study Considered

\begin{tabular}{lcccc}
\hline \multicolumn{1}{c}{ Study } & Design & Selection bias & Reporting bias & Reference standard \\
\hline Randolph (2002) & High & High & High & High \\
Hoyes (2004) & High & High & Low & High \\
Bal (2006) & Unclear & High & High & High \\
Santra (2011) & High & High & High & High \\
Giovanella (2013) & Low & Low & Low & Low \\
\hline
\end{tabular}

\section{Quantitative Analysis (Metaanalysis)}

The pooled rate of successful ablation was $69 \%$ (Fig. 2); high heterogeneity was found ( $\mathrm{I}^{2}$ test, $\left.85 \%\right)$, and publication bias was absent (Egger test, $P=0.57$ ). To investigate the heterogeneity found in the pooled rate of success of ${ }^{131}$ I therapy, a metaregression was performed to analyze the correlation between the ${ }^{131} \mathrm{I}$ activity administered and the success of ${ }^{131}$ I therapy. As shown in Figure 3, the higher the ${ }^{131} \mathrm{I}$ activity, the higher the rate of success $(P=0.02)$.

\section{DISCUSSION}

The aim of this systematic review and metaanalysis was to produce evidence-based data on the reliability of ${ }^{131} \mathrm{I}$ therapy as a noninvasive procedure to complete thyroid ablation after lobectomy in patients with DTC. Indeed, to our knowledge, this is the first high-level evidence study to focus specifically on this issue. An extensive database search was performed without time or language restrictions, and inclusion criteria were defined a priori.

Overall, ${ }^{131}$ I therapy was found to be an effective and safe strategy for completing thyroid ablation after lobectomy. As the main result, the pooled rate of successful ablation was $69 \%$, with better results in patients receiving a single administration of about 3.7 GBq. Particularly, ${ }^{131}$ I thyroid lobe ablation, which was performed during thyroid hormone withdrawal, presented a very high rate of complete ablation, ranging from $75 \%$ to $90 \%$ when a relatively high activity of ${ }^{131} \mathrm{I}$ (i.e., $3.5-3.7 \mathrm{GBq}$ ) was used. By contrast, less than $60 \%$ of patients treated with a single activity of about $1.1 \mathrm{GBq}$ achieved lobe ablation.

When we applied to these studies the concept of response to initial therapy risk, as defined by the 2015 American Thyroid

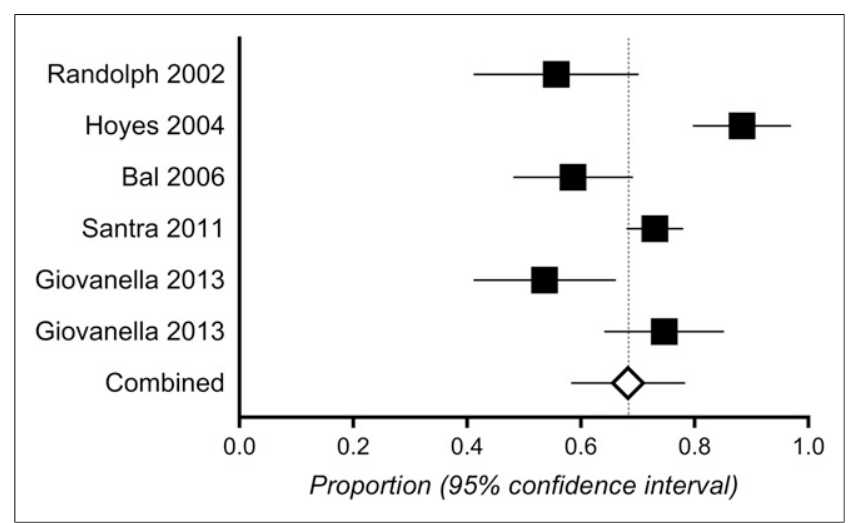

FIGURE 2. Proportion of rate ablation (with $95 \%$ confidence interval) of studies included in metaanalysis, with pooled result represented by diamond.
Association guidelines, incomplete structural responses were recorded in only 14 of 695 (2\%) patients enrolled in our analysis; all of these come from a single series $(8)$.

Incomplete biochemical responses were observed in $8 \%-24 \%$ of patients, with higher rates $(24 \%)$ being recorded in patients receiving lower radioiodine activities $(\sim 1.1 \mathrm{GBq})$ and lower rates (from $8 \%-18 \%$ ) in patients receiving higher activities of radioiodine $(\sim 3.7 \mathrm{GBq})(5,9)$; these latter rates are not far from rates reported following the conventional thyroid ablation strategy (i.e., total thyroidectomy followed by ${ }^{131}$ I ablation).

Finally, we systematically analyzed ${ }^{131}$ I therapy-related side effects on the basis of the 3 studies that reported reliable information. Overall, significant neck pain due to thyroiditis was reported in up to $18 \%$ of patients in 2 studies $(2,7)$. Mild to moderate neck pain occurred in 50\%-66\% of patients in another study, depending on the activity administered: however, in most cases, symptoms resolved after oral paracetamol (500-1,000 mg) administration for a few days; in rare cases, a short course of prednisone (20-40 mg/ $\mathrm{d}$, tapered over 7-10 d) was needed (9). These data are encouraging, albeit limited; however, two of the studies analyzed were prospectively designed, which increased the reliability of our results.

In summary, ${ }^{131} \mathrm{I}$ ablation after lobectomy is an effective alternative to completion thyroidectomy, especially when performed by administering activities of about $3.7 \mathrm{GBq}$, and has no or minor side effects.

Some limitations, however, should also be disclosed: first, the definition of thyroid ablation was not consistent among the studies, mostly because of the adoption of different thyroglobulin assays and cutoff points. On the other hand, applying a fixed quantitative criterion was debatable, as different assays were used, with associated differences in functional sensitivity and calibration (10). Notably, qualitative and quantitative radioiodine scanning remains the most reliable way to properly authenticate thyroid ablation, especially in the context of clinical research (11). We therefore opted for a composite qualitative criterion, adopting negative scan and thyroglobulin levels below the institutional cutoff point for a given center as the criterion for ablation.

Second, the high rate of excellent response could be related to the prevalence of low-risk DTC patients in these cases. On the other hand, a relatively high number of follicular and Hürthle cell thyroid cancers were also included.

Third, it was not possible to retrieve and analyze data on the longterm outcomes of patients. Interestingly, previously published large cohort studies found improved overall and disease-free survival after ${ }^{131}$ I lobar ablation. Using the National Cancer Database, Kiernan et al. (12) retrieved data on 32,119 of 170,330 (20\%) DTC patients treated by thyroid lobectomy between 1998 and 2011. Their mean 


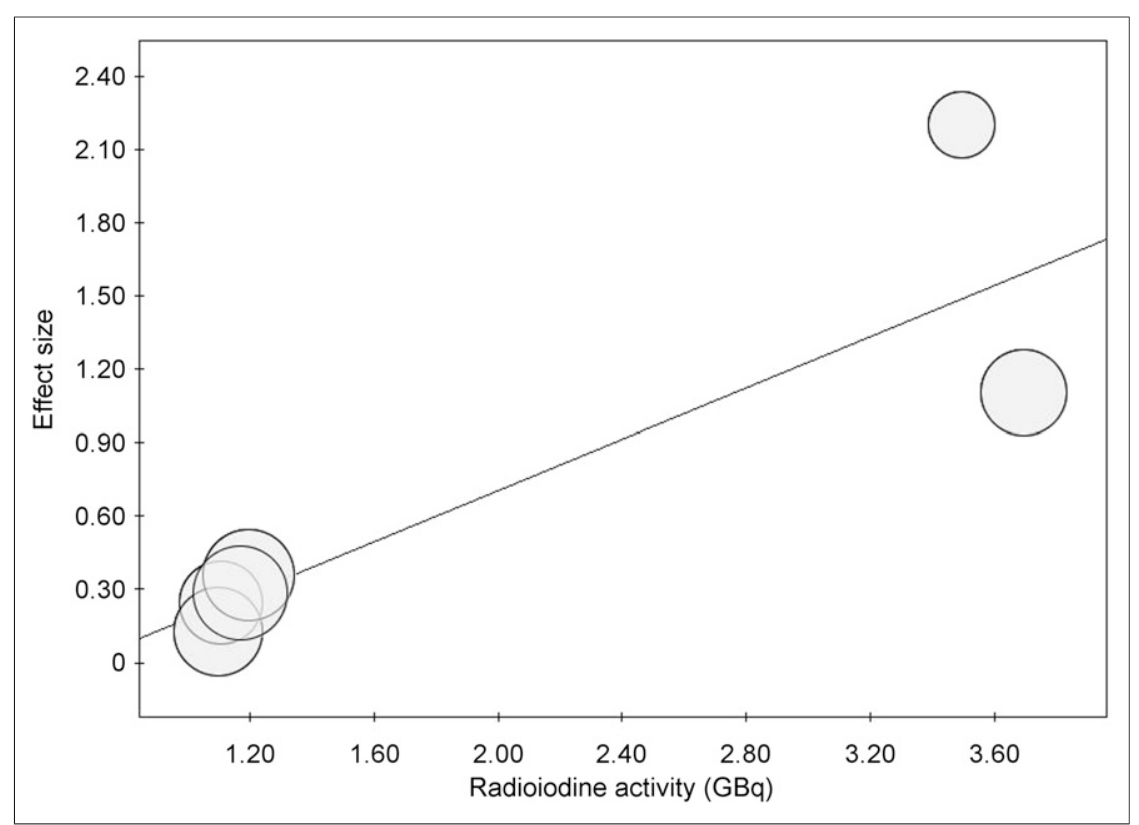

FIGURE 3. Metaregression scatterplot showing correlation between ablation rate (log) and radioiodine activity. Each circle represents study in metaanalysis, and size of circle is proportional to sample size.

age on diagnosis was $48 \mathrm{y} ; 4 \%$ had extrathyroidal extension, $4 \%$ had positive lymph nodes, and less than $1 \%$ had distant metastases. ${ }^{131} \mathrm{I}$ therapy was administered to $24 \%$ of patients in the thyroid lobectomy cohort and accounted for $10 \%$ of the overall ${ }^{131} \mathrm{I}$ use. On multivariate analysis, ${ }^{131}$ I therapy use was associated with an age of less than 45 y (odds ratio, 1.51), community facilities (odds ratio, 1.26), tumors larger than $1 \mathrm{~cm}$ (odds ratio, 5.67), stage II or III (odds ratio, 1.54 and 2.05), positive lymph nodes (odds ratio, 1.78), and extrathyroidal extension (odds ratio, 1.36). On both univariate and multivariate analyses, ${ }^{131} \mathrm{I}$ after lobectomy was associated with improved survival at both 5- and 10-y follow-up examinations $(97 \%$ vs. $95 \%$ and $91 \%$ vs. $89 \%$, respectively; hazard ratio, 0.53 ; confidence interval, 0.38-0.72 $[P<0.001])(12)$.

Barbesino et al. (13) retrospectively compared ${ }^{131} \mathrm{I}$ lobe ablation and completion thyroidectomy in a series of 134 patients affected

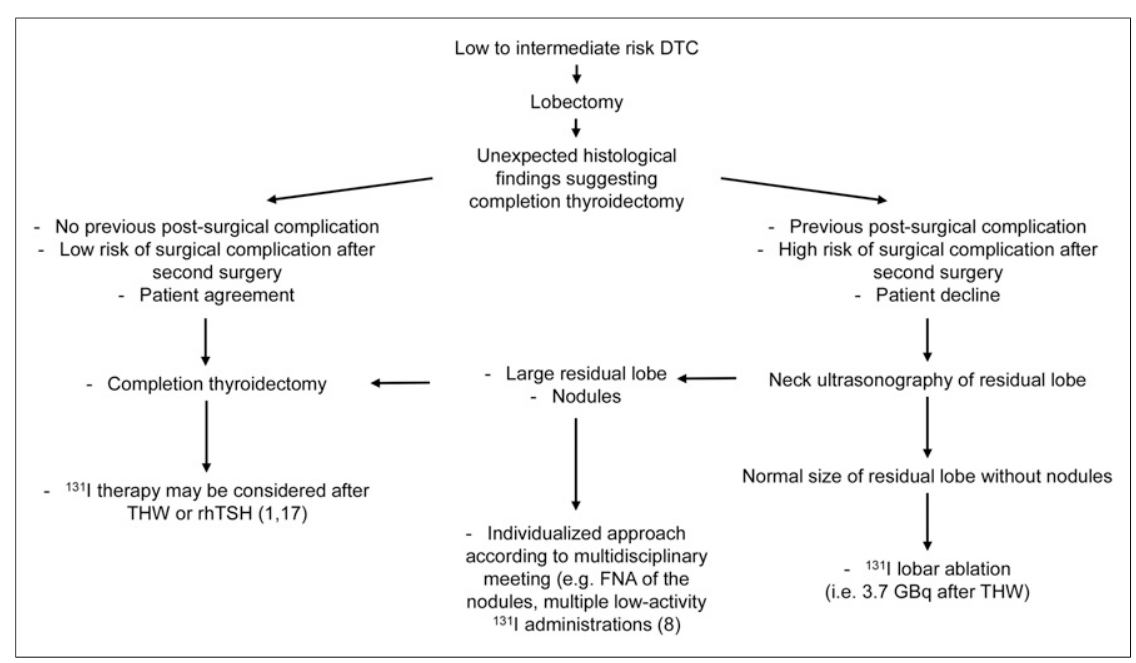

FIGURE 4. Proposed flowchart for ${ }^{131} \mid$ lobar ablation. FNA $=$ fine-needle aspiration; $r$ hTSH $=$ recombinant human thyroid-stimulating hormone; THW = thyroid hormone withdrawal. by follicular thyroid carcinoma treated between 1983 and 2008. Thirty-seven (27.6\%) had ${ }^{131} \mathrm{I}$ lobe ablation with $1.1 \mathrm{GBq}$ of ${ }^{131} \mathrm{I}$, $68(50.7 \%)$ had completion thyroidectomy, and $29(21.6 \%)$ had initial total thyroidectomy. The investigators proved that these approaches were equally effective in preparing patients for conventional ${ }^{131} \mathrm{I}$ treatment, and whole-body scanning was associated with similar long-term outcomes (after 47$95 \mathrm{mo}$ ). In line with our results, Barbesino et al. found a higher rate of patients with detectable thyroglobulin $(0.2-2.2 \mathrm{ng} / \mathrm{mL})$ after ${ }^{131} \mathrm{I}$ lobe ablation than after completion or total thyroidectomy (13).

One of the possible explanations for this difference in terms of thyroglobulin response may be related to thyroglobulin half-life, which is about $28 \mathrm{~h}$ (14) after total thyroidectomy, with a nadir reached in 3-4 wk (15). Vice versa, even if precise data on thyroglobulin half-life after radioiodine lobe ablation are not available, its concentration may slowly decline over the years (16).

Fourth, recommended thyroid-stimulating hormone cutoff levels to perform ${ }^{131} \mathrm{I}$ therapy are not inferable from these studies, considering that the mean thyroid-stimulating hormone levels reported ranged from 11 to $76 \mu \mathrm{IU} / \mathrm{mL}$. However, a clinical hypothyroidism related to adequate thyroid hormone withdrawal was the most frequent approach. This endogenous thyroid-stimulating hormone stimulation seems to be the most adequate preparation for ${ }^{131}$ I therapy.

Another limitation is the lack of information about the residual lobe before administering ${ }^{131} \mathrm{I}$. Indeed, the dimension of the lobe is an important issue, considering its influence on successful ablation. In addition, in patients with a large residual lobe, symptomatic ${ }^{131} \mathrm{I}-$ related thyroiditis could be more frequent. One of the 5 studies evaluated the volume of residual lobe (9). Indeed, in the study by Giovanella et al. (9), one of the inclusion criteria to perform lobe ablation with ${ }^{131} \mathrm{I}$ was a normal residual lobe (i.e., men $<12.5 \mathrm{~cm}^{3}$, women $<9 \mathrm{~cm}^{3}$ ) without nodules on ultrasound examination. From this point of view, we suggest careful neck ultrasonography to estimate the size of the lobe and to inform the ${ }^{131} \mathrm{I}$ administration strategy (Fig. 4).

Finally, it is difficult to infer the clinical intent of radioisotopic lobectomy (i.e., ablation, to lower thyroglobulin levels, or adjuvant, to prevent recurrences) in the selected studies. In fact, the rigorous distinction between the ablative, adjuvant, and therapeutic aims of postoperative ${ }^{131} \mathrm{I}$ administration was only recently introduced $(1,17)$, making its retrospective application impossible. On the other hand, considering that an effective ablation is often associated with an excellent response to treatment and a good prognosis (1), the possibility of achieving undetectable or very low levels of thyroglobulin after ${ }^{131} \mathrm{I}$, even after lobectomy, could predict a good outcome identifying the patients at lower risk of disease relapse. 


\section{CONCLUSION}

The need for completion thyroidectomy after lobectomy could increase in the near future because of new DTC guidelines. Thus, a noninvasive, feasible, and safe alternative to a second-step surgery is desirable. Lobar ablation with ${ }^{131} \mathrm{I}$ is effective, especially when high ${ }^{131}$ I activities are used. However, the rate of incomplete biochemical response to initial treatment appears to be slightly higher than in the classic total thyroid ablation scheme, probably because of differences in the disappearance kinetics of thyroglobulin after ${ }^{131} \mathrm{I}$ lobe ablation. Further prospective studies assessing the reliability of this procedure using standardized criteria for interpretation of thyroid tissue ablation are needed. Overall, radioisotopic lobectomy should be currently considered for patients with low- to intermediate-risk DTC requiring completion treatment after lobectomy due to specific individual features, risk factors, or patient preferences $(1,17)$ who are not eligible for a second surgery or prefer to avoid an additional invasive procedure.

\section{DISCLOSURE}

No potential conflict of interest relevant to this article was reported.

\section{KEY POINTS}

QUESTION: is radioiodine lobectomy a feasible, effective, and safe procedure in patients with an unexpected diagnosis of intermediateto high-risk DTC after lobectomy for an indeterminate thyroid nodule or in the case of unexpected extrathyroidal extension or lymph node metastases in patients with DTC considered, a priori, at low risk?

PERTINENT FINDINGS: Lobar ablation with ${ }^{131} \mid$ is effective, especially when high ${ }^{131}$ I activities are used. However, the rate of biochemical incomplete response to initial treatment seems to be slightly higher than in the classic scheme of total thyroid ablation, likely because of differences in disappearance kinetics of thyroglobulin after ${ }^{131} \mathrm{I}$ lobar ablation.

IMPLICATIONS FOR PATIENT CARE: The need for completion thyroidectomy after lobectomy could increase in the near future because of new DTC guidelines. Then, a noninvasive, feasible, and safe alternative to a second-step surgery will be desirable.

\section{REFERENCES}

1. Haugen BR, Alexander EK, Bible KC, et al. 2015 American Thyroid Association management guidelines for adult patients with thyroid nodules and differentiated thyroid cancer: the American Thyroid Association Guidelines Task Force on Thyroid Nodules and Differentiated Thyroid Cancer. Thyroid. 2016;26:1-133.
2. Untch BR, Palmer FL, Ganly I, et al. Oncologic outcomes after completion thyroidectomy for patients with well-differentiated thyroid carcinoma. Ann Surg Oncol. 2014;21:1374-1378.

3. Tan MP, Agarwal G, Reeve TS, Barraclough BH, Delbridge LW. Impact of timing on completion thyroidectomy for thyroid cancer. Br J Surg. 2002;89:802-804.

4. Liberati A, Altman DG, Tetzlaff J, et al. The PRISMA statement for reporting systematic reviews and meta-analyses of studies that evaluate health care interventions: explanation and elaboration. Ital J Public Health. 2009;4:354-391.

5. Randolph GW, Daniels GH. Radioactive iodine lobe ablation as an alternative to completion thyroidectomy for follicular carcinoma of the thyroid. Thyroid. 2002;12: 989-996.

6. Hoyes KP, Owens SE, Millns MM, Allan E. Differentiated thyroid cancer: radioiodine following lobectomy-a clinical feasibility study. Nucl Med Commun. 2004;25:245-251.

7. Bal CS, Kumar A, Chandra P, Dwivedi SN, Pant GS. A prospective clinical trial to assess the efficacy of radioiodine ablation as an alternative to completion thyroidectomy in patients with differentiated thyroid cancer undergoing sub-total thyroidectomy. Acta Oncol. 2006;45:1067-1072.

8. Santra A, Bal S, Mahargan S, Bal C. Long-term outcome of lobar ablation versus completion thyroidectomy in differentiated thyroid cancer. Nucl Med Commun. 2011;32:52-58.

9. Giovanella L, Piccardo A, Paone G, Foppiani L, Treglia G, Ceriani L. Thyroid lobe ablation with iodine-131 in patients with differentiated thyroid carcinoma: a randomized comparison between 1.1 and $3.7 \mathrm{GBq}$ activities. Nucl Med Commun. 2013;34:767-770.

10. Verburg FA, Mäder U, Grelle I, Giovanella L, Reiners C, Hänscheid H. Only a rapid complete biochemical remission after ${ }^{131} \mathrm{I}$-therapy is associated with an unimpaired life expectancy in differentiated thyroid cancer. Horm Metab Res. 2017;49:860-868.

11. Salvatori M, Perotti G, Giovanella L, Dottorini ME. Can an undetectable value of TG and a negative neck ultrasound study be considered reliable methods to assess the completeness of thyroid ablation? Eur J Nucl Med Mol Imaging. 2010;37: 1039-1040.

12. Kiernan CM, Parikh AA, Parks LL, Solórzano CC. Use of radioiodine after thyroid lobectomy in patients with differentiated thyroid cancer: does it change outcomes? J Am Coll Surg. 2015;220:617-625.

13. Barbesino G, Goldfarb M, Parangi S, Yang J, Ross DS, Daniels GH. Thyroid lobe ablation with radioactive iodine as an alternative to completion thyroidectomy after hemithyroidectomy in patients with follicular thyroid carcinoma: long-term follow-up. Thyroid. 2012;22:369-376.

14. Giovanella L, Ceriani L, Maffioli M. Postsurgery serum thyroglobulin disappearance kinetic in patients with differentiated thyroid carcinoma. Head Neck. 2010; 32:568-571

15. Giovanella L, Clark PM, Chiovato L, et al. Thyroglobulin measurement using highly sensitive assays in patients with differentiated thyroid cancer: a clinical position paper. Eur J Endocrinol. 2014;171:R33-R46.

16. Padovani RP, Robenshtok E, Brokhin M, Tuttle RM. Even without additional therapy, serum thyroglobulin concentrations often decline for years after total thyroidectomy and radioactive remnant ablation in patients with differentiated thyroid cancer. Thyroid. 2012;22:778-783.

17. Tuttle RM, Ahuja S, Avram AM, et al. Controversies, consensus, and collaboration in the use of ${ }^{131} \mathrm{I}$ therapy in differentiated thyroid cancer: a joint statement from the American Thyroid Association, the European Association of Nuclear Medicine, the Society of Nuclear Medicine and Molecular Imaging, and the European Thyroid Association. Thyroid. 2019;29:461-470. 